subject proved that the prostate will only admit the terminal joint of the forefinger without lacerating, and a personal examination of all the specimens in the various museums in London a few years ago, showed me that in no single instance had a stone been removed from the bladder without lacerating or cutting the gland. MMr. Crowther refers to a lecture of Mr. Erichsen's ; but, unless I am very much mistaken, that gentleman has considerably modified his views, and believes that in practical lithotomy, small calculi excepted, a stone must either be cut out or torn out. The objection to the method of so-culled dilatation is, that it involves a laceration or bruising of the plexus of veins surrounding the prostate, and hence the common cause of death after lithotomy is pyæmia; and the procedure has, moreover, to answer for those disasters, by no means few in number, which have befallen lithotomists. Those surgeons who extract calculi by the so-called process of dilatation, which is in reality laceration, lose far more patients than those operators who cut rather than tear. No observation can be passed on the single instance related by Mr. Crow ther, as he has omitted, quite accidentally I should say, to stat what was the size of the stone he removed; nor can any remark be made on the Emperor Napoleon's case, as the details are still withbeld from the profession.

I remain, Sir, your obedient servant,

Portman-square, Nov. 4th, 1873. W. F. Tuevan.

\section{HEALTH OFFICERS AND "QUARTERLY RETURNS."}

To the Editor of The LANCET.

Srr,-I am glad to see that your correspondent, "Nil Desperandum," has raised the subject of the recent demand by the Local Government Board for returns of pauper sickness and deaths from medical officers of health. As I have, apparently like your correspondent, to deal with more rural sanitary authorities than one, I felt it necessary to decide upon what course I should take with respect to the forms which were forwarded to me by Mr. Lambert, and the course which I have adopted is this: to inform the sanitary authorities in each case of the information which the Government required and how it might be obtainedviz, by calling on the district medical officers to fill up their returns of medical relief in such a way as would enable me to obtain from them the statistics required by the Local Government Board, and by arranging with the registrars of births and deaths for copies of returns of deaths, to be afterwards checked for pauper deaths by the relieving officers. My suggestion has been somewhat differently received by different boards; some have readily fallen in with it, others have either directly or indirectly objected to adopt it. The result, of course, will be that where the information is supplied to me I shall forward it to the Local Government Board, where it is not I shall intimate the reason why I have not done so. Probably Mr. Stansfeld and his advisers will not be much surprised at this result, as it is pretty evident that they have simply made a fishing attempt to get what they could, and have pitched these quarterly returns at the heads of the medical officers of health in the devout hope that the majority of them would fight out the difficulties of obtaining them with the local authorities. I trust that my sanitary brethren will not be so easily deluded into under taking what should be the work of the central board. I cannot help looking on this move of the authorities at Whitehall as a piece of diplomacy which is by no means creditable to them, and which goes far to justify the charges of blundering which have been brought against them in regard to their attempts at sanitary organisation generally. Instead of drawing up a memorandum on the subject of the statisties which they required, pointing out how they were to be obtained, and forwarding it to the sanitary authorities whose concurrence is necessary in order to realise this object, the Local Government Board has thought it consistent with its dignity to make the medical officers of health its cat's-paw in attacking the boards of guardians. Knowing full well, unless it was grossly ignorant on the subject, that all sorts of difficulties lay in the way of obtaining these returns, and that they cannot be procured without some expense, unless the officer of health is prepared to ask the medical and other officials of the board of guardians to do him the favour of helping him-a position in which no officer of health is likely to place himself,-it must have intended either to saddle that expense upon the officer of health, or to put him in the invidious position of asking the local board to incur it. For my own part I can only say that I do not intend to spend a penny in obtaining these returns. I quite concur with the Local Government Board as to their importance, and am prepared to do all that can be reasonably expected of me in tabulating and arranging the materials for them if they are supplied to me; but I shall certainly not ask other people to do as a favour what the Local Government Board can obtain as a matter of duty if they have any power in the matter, and what they have no right to ask at all if they have not. It is a good illustration of the blundering way in which the whole affair has been perpetrated, that the forms are sent down at the end of the quarter without any preliminary notice that they would be required, and when it is practically impossible in many cases to obtain the information which is wanted, inasmuch as everyone who has had much experience of the returns of medical relief usually sentinto boarde of guardians know that they are often so hastily made up as to be very untrustworthy data for statistical inductions. The fact is that if they are to be used for this purpose, for which they have neither been intended nor used hitherto, the attention of those by whom they are made should be called to the alteration, and they should be informed that more accuracy is required in filling them up than has been hitherto thought necessary. This notice would, with propriety, come from the Local Government Board, and not from a brother professional man, upon whom the district medical officers in many cases already look with some jealousy. We have heard a good deal of late of how little the Medical Department of the Local Government Board has been consulted in matters of sanitary organisation, and I sincerely trust that it has had no hand in this proceeding, which is as good a specimen as could be given of " how not to do it." I am, Sir, yours \&c.,

a Medical Officer of Health.

November 3rd, 1873.

\section{CASE OF POISONING BY LAUDANUM.}

SUBCUTANEOUS INJECTION OF LIQUOR AMMONIA FORTISSIMUS.

To the Editor of THE LANCET.

SrR,-I was called to M. L. H- on October 28 th, 1873 , at half-past nine A.M., and found him quite insensible. Pupils contracted to a point, face much congested, and breathing laborious. I was shown a bottle containing a little laudanum, and which had been found near the patient. A stomach-pump would have been used had his friends not objected. Sulphate of zinc was given in large doses frequently, but, as it did not act, mustard was combined with it, and produced fres vomiting. He was kept constantly walking about, and partook freely of coffee. Powerful purgative medicine was administered, but without effect, during the first three or four hours that I was in attendance, and half a drachm of tincture of belladonna was given hourly. By 2.30 P.M. the patient was able to converse with his friends, and explained that be had taken half an ounce of laudanum, which he had procured in small quantities at five different shops. At 4 o'clock, all the symptoms having subsided, he was allowed to go to bed. At 6 P.M., the bowels not yet being open, an enema of soapy water was administered, which acted. He was seen again at 10.30 P M., when he seemed not quite so sensible; pulse 108, full. At 11.30 P.M. I found him a great deal worse; there was lividity of the face, pulse thready, great difficulty of breathing, total insensibility, pupils contracted, and skin cold. Mustard poultices were applied over the heart, to the back of the neck, and the calves of the legs. He took frequent doses of sal volatile, but with little benefit. Mr. Meates and I decided to inject subcutaneously one drop of liquor ammoniæ fortissimus, diluted with four drops of warm water, after which he was kept walking about the room. An hour later the subcutaneous injection was re- 
peated; the pupils then dilated a good deal. Coffee and sal volatile were continued to be administered, and half a drachm of tincture of belladonna was also given for a dose. At 2 A.M., finding the pulse very flagging, and there being greater difficulty in keeping the patient walking, the liquor ammoniæ fortissimus was injected as before. His eyelids began to droop very much, but notwithstanding this, at 2.50 A.M., he asked for his watch to wind it up. At 3.8 A.M. he sank on his knees and expired. - I am, Sir, yours, \&c. Edmund Harteey, L.K. \& Q.C.P.I.

Warwick-square, S.W., Nov. 3rd, 1873.

\section{S M A L L-P O X I N LEED S. To the Editor of The LANowt.}

SIR,-I notice in your last week's number an intimation that an inspection was necessary in my new Leeds district, owing to an outbreak of small-pox. Allow me to cite the whole facts of the matter.

On September 24th, 1873, a person came from Skelton, near Saltburn-by-the-Sea, with the disease upon him. $\mathrm{He}$ was ill nine days, and died. My district inspector reported the case, and I was at once upon the spot. By this time several people had caught the disease. I soon ascertained the names and residences of all, and showed them the necessity of keeping from public places, or even visiting their neighbours. I supplied them liberally with carbolic-acid powder. Saw myself that the ashpits and privies were emptied. The surroundings of those ashpits, \&c., were well covered over with the powder. The whole system of drainage was examined by my able inspector, Mr. Newhouse, and myself, and found imperfect. The street in which those ashpits and privies are situated is not drained at all; the soil must therefore be in a very unsafe state. By continued watchfulness over the district, the epidemic was stamped out in six days from my first visit to the place. The number infected was 16 , the deaths 3 .

I laid the state of the district before my committee, which met on the 27 th inst., and asked that they should at once have the drains in that district so improved as $I$ thought would make it, as it ought to be, a very healthy locality, and also that drains be laid in all the back streets in which there are none at present. I could give you more elaborate details from $m y$ report of the 27 th inst., but know your space would not admit them. Hoping, in justice to me, you will publish these few facts,

I am, Sir, yours, \&c.

GEO. GoLdre,

Oetober 29th, 1873.

Medieal Officer of Health for the Borough of Leeds

\section{AN ARMY MEDICAL GRIEVANCE. \\ To the Editor of THe Lancet.}

Sir,-I take leave to address you for the purpose of bringing before the notice of your readers an act of injustice of which the old officers of the African medical service are about to be made the subjects. By a recent warrant, issued in the current year, it is provided that for the future all medical officers entering the African service will receive double pay while on the Coast and count also double time. But it appears upon inquiry that these double and special advantages are not to apply to those officers now in the African medical service. And, furthermore, the latter are not allowed the privilege of being transferred to the general service, in order that they may volunteer for their old work (and thus, by a side wind, glean the advantages held out to all their other brethren). So that, as things now stand, a surgeon-major in the African section of more than twelve zears' actual service may be in medical charge of an entire station on the West Coast, drawing 3.7s. $6 d$. per diem, while one of his juniors as surgeon will be taking $20 s$, and a surgeon of five zears' service $25 s$. per diem, and so on. It would appear, therefore, that length of service is in this case a decided disadvantage to an officer, and the bad moral effect in the army generally produced by such an arrangement cannot be questioned.

The injustice of the measure seems so very obvious that I trust you will afford space for these brief details in your columns. - I am, Sir, jour obedient servant,

London, Nov, 4th, 1873 .

\section{ARMY HOSPITAL STOPPAGES.}

\author{
To the Editor of THE LANCET.
}

Sir,-By "Army Circular" bearing date September 26th, 1873, a weekly return is called for from medical regimental officers, of non-commissioned officers and men who have been treated in hospital on account of sickness \&c. "due to their own misconduct."

Now, the knotty point is what diseases are to be included in this category. An offence is implied by the punishment accorded-viz., total stoppage of the offender's pay.

If the offence be a breach of military law, the medical officer, as he is constantly reminded, has no jurisdiction whatever; and if it be a moral offence, who is to decide? If it comes under the latter denomination, we would suggest to the bewildered medical officer that the point at issue be referred for decision to the nearest military chaplain. 1 remain, Sir, yours \&c.,

Plymouth, October 3rd, 1873. ONE in a Fix.

\section{LIVERPOOL.}

(From an occasional Correspondent.)

THe session at the Liverpool School of Medicine was opened under more than usually farourable auspices, forty first-year's men representing the new entries. This is the largest accession in the history of the school, and brings the total number of students engaged this session in the various classes to one over the hundred. Doubtless the opening of the new buildings has in a measure contributed towards swelling the ranks on this occasion.

Mr. J. P. Heywood has supplemented his gift of $\$ 1000$ towards the expenses of the new museum and other buildings by an additional donation of $\$ 500$. The total cost of the alterations, inclusive of the necessary fittings, is close upon $\$ 5500$; with the exception of about $\$ 400$, which still remains to be raised, this amount has been subscribed by the profession and the public, Mr. Hey wood contributing the munificent proportion of $£ 1500$. The new museum is not yet completely fitted, but is in active progress, and it is hoped that the preparations will be transferred to their new home in the course of a few days.

The Physiological Laboratory is, perhaps, the most striking portion of the additions; it is well worth a visit, especially by those contemplating providing a similar department in connexion with other schools of medicine. The new arrangements, under the superintendence of Dr. Caton and Mr. Rushton Parker, are already found to answer in an admirable manner the requirements of the students engaged in practical physiology. Credit must be given to the College of Surgeons for the stimulus they have recently given in this direction by the altered curriculum. If their regulations are properly carried out at the schools, the students' acquaintance with the microscope and other instruments equally useful in practice will be, to a certain extent, guaranteed.

Mr. John Torr, M.P., who opened the new buildings on October 1st, and afterwards distributed the prizes, has, with the view of providing a permanent memento of the additional stimulus that has thus been given to medical education in Liverpool, presented $£ 100$ to the Council of the School for investment, the interest of which is to provide a medal commemorative of the opening of the new buildings. The Council have decided that this prize shall be awarded for anatomy and physiology, and that it shall bear the name of the donor, "the Torr Medal."

At another important centre of medical work, the $\mathrm{Me}$ dical Institution, the session has been inaugurated with more than usual éclat.

The President's soirée of 1873 will long be looked back upon as one of the most enjoyable réunions in connexion with our Medical Society.

Liverpool, Nov. 5th, 1873.

Oven three hundred tons"of diseased fish were seized and destroyed at Billingsgate during the past four months. 